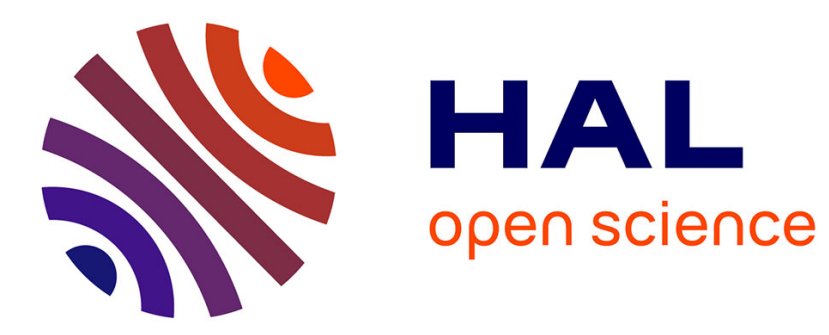

\title{
The Rotational Spectrum of Diethyl Ketone
}

Ha Vinh Lam Nguyen, Wolfgang Stahl

\section{- To cite this version:}

Ha Vinh Lam Nguyen, Wolfgang Stahl. The Rotational Spectrum of Diethyl Ketone. ChemPhysChem, 2011, 12 (10), pp.1900-1905. 10.1002/cphc.201001021 . hal-03183171

\section{HAL Id: hal-03183171 \\ https://hal.science/hal-03183171}

Submitted on 27 Mar 2021

HAL is a multi-disciplinary open access archive for the deposit and dissemination of scientific research documents, whether they are published or not. The documents may come from teaching and research institutions in France or abroad, or from public or private research centers.
L'archive ouverte pluridisciplinaire HAL, est destinée au dépôt et à la diffusion de documents scientifiques de niveau recherche, publiés ou non, émanant des établissements d'enseignement et de recherche français ou étrangers, des laboratoires publics ou privés. 


\title{
The rotational spectrum of diethyl ketone
}

\author{
H.V.L. Nguyen ${ }^{[a]}$ and W. Stahl
}

We report on the rotational spectrum of diethyl ketone, $\mathrm{C}_{2} \mathrm{H}_{5}-\mathrm{C}(=\mathrm{O})-\mathrm{C}_{2} \mathrm{H}_{5}$, as observed by Fourier transform microwave spectroscopy under pulsed molecular beam conditions. Almost all lines were split into narrow quartets in a range from $10 \mathrm{kHz}$ up to 2 $\mathrm{MHz}$ arising from the hindered rotation of the two equivalent terminal methyl groups. In a global analysis using the xiam code based on the rho axis method three rotational constants, five quartic centrifugal distortion constants, the torsional barrier of the terminal methyl groups, and the angles between the principal inertial axes and the internal rotor axes were determined. The methyl torsional barrier was found to

\section{Introduction}

Ketones represent a very important class of chemical compounds in chemistry, industry, and pharmacy. They are widely used as solvents or intermediates for chemical reactions. Surprisingly, there are only very few studies on the molecular geometries of ketones in the gas phase. The most simple aliphatic ketone acetone has been investigated already very early. ${ }^{[1,2]}$ Also microwave studies on trifluoroacetone, ${ }^{[3]}$ methyl ethyl ketone, ${ }^{[4]}$ and methyl vinyl ketone ${ }^{[5]}$ have been reported in the past. To our knowledge, no larger aliphatic ketones with more than four carbon atoms have been studied in the microwave region before. Acetyl acetone, ${ }^{[6]}$ a ketone with two carbonyl groups, and the cyclic ketones acetophenone, ${ }^{[7]}$ phenyl acetone, ${ }^{[8]}$ benzophenone ${ }^{[9]}$ and 2 -indanone ${ }^{[10]}$ have also been published. Diethyl ketone is an interesting molecule due to its symmetry properties. We were interested to find out how the two ethyl groups are oriented. By rotating both ethyl groups around the $\mathrm{O}=\mathrm{C}-\mathrm{C}$-bonds many geometries of diethyl ketone can be generated. It is an interesting question how many geometries correspond to energy minima and which of those conformers can be observed under molecular beam conditions. Moreover, it is interesting to find out, whether the stable conformers have $\mathrm{C}_{2 \mathrm{v}}, \mathrm{C}_{2}$, or $C_{S}$ symmetry or whether they have no symmetry at all $\left(C_{1}\right)$. We tried to answer these questions by studying diethyl ketone by a be $771.93(27) \mathrm{cm}^{-1}$. In total 199 lines were fitted to a standard deviation of $3.5 \mathrm{kHz}$.

The experimental work was supplemented by quantum chemical calculations. Two-dimensional potential energy surfaces describing the rotation of both ethyl groups against the $C=O$ frame were calculated with the MP2 method as well as the DFT method using the 6-311++G(d,p) basis set and the B3LYP functional, respectively. Combining the experimental and theoretical results, an effective structure with $C_{2 v}$ symmetry was deduced for the diethyl ketone molecule. Moreover, the torsional barrier of the methyl groups was determined by ab initio methods.

combination of molecular beam Fourier transform microwave (MB-FTMW) spectroscopy and ab initio calculations.

Methyl internal rotation is a further motivation for this work. In the studies of Pozdeev et. al. ${ }^{[4]}$ on the microwave spectrum of methyl ethyl ketone, a barrier to methyl internal rotation $\mathrm{CH}_{3}-\mathrm{CH}_{2}-\mathrm{CO}$ of $795(10) \mathrm{cm}^{-1}$ was found. In the case of diethyl ketone, the situation is similar. Therefore, we expected to be able to resolve the splitting due to the internal rotation of the two methyl groups. We were also interested to find out, whether the barrier significantly changes.

\section{Experimental Section}

The two MB-FTMW spectrometers used for this study were modified versions of those described in ${ }^{[11]}$ and ${ }^{[12]}$. The spectrometers can be used in two different modes, the single frequency mode and the broadband scan mode. The single frequency mode allows to observe a spectral range of only about $1 \mathrm{MHz}$ limited by the width of the resonator modes. In the scan mode a wide frequency range can be automatically scanned by a series of single frequency experiments.

[a] H.V.L. Nguyen

Institute of Physical Chemistry

RWTH Aachen University

Landoltweg 2, D-52074 Aachen, Germany

Fax: +492418092365

E-mail: nguyen@pc.rwth-aachen.de 
Diethyl ketone was purchased from Merck Schuchardt OHG, Hohenbrunn, Germany and used without further purification. A mixture of approximately $1 \%$ diethyl ketone in helium at a total pressure in the range from 50 to $200 \mathrm{kPa}$ was expanded through a pulsed nozzle into a vacuum chamber to generate the molecular beam. Helium was used as carrier gas since the rotational temperature is higher than in neon or argon. This enabled us to observe a wider range of $\mathrm{J}$ and $\mathrm{K}$ states, which is important for the determination of some centrifugal distortion and internal rotation parameters.

In the single frequency mode all lines are split into doublets due to the Doppler effect. All transition frequencies were split into four torsional components due to the internal rotation of two equivalent methyl groups. The line width was in the range from 10 to $25 \mathrm{kHz}$, the line positions could be determined with an accuracy of about $4 \mathrm{kHz}$. This is larger than the usual accuracy which we could achieve with our spectrometers as will be discussed below. A typical spectrum is shown in Figure 1.

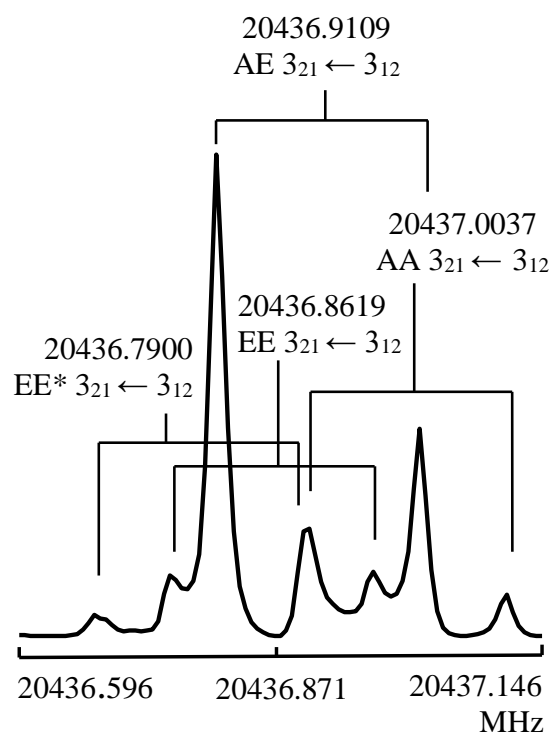

Figure 1. The $3_{21} \leftarrow 3_{12}$ transition of diethyl ketone. The experimental resolution was $4 \mathrm{kHz}$, the typical experimental line width $24 \mathrm{kHz}$. The large splitting is due to the Doppler effect (indicated by brackets). For this spectrum 74 FIDs were co-added.

\section{Spectral analysis}

\section{Quantum chemical calculations}

In order to predict the conformers of diethyl ketone and their respective rotational constants, quantum chemical calculations were carried out using the Gaussian 03 program package. ${ }^{[13]}$ We started with a planar heavy atom geometry similar to that one shown in Figure 2 and optimized it at the MP2/6-311++G(d,p) level of theory. This method and basis set was chosen since it turned out to be reliable in a number of similar cases, e.g. isopropenyl acetate ${ }^{[14]}$ and ethyl pivalate. ${ }^{[15]}$ In contrast to our

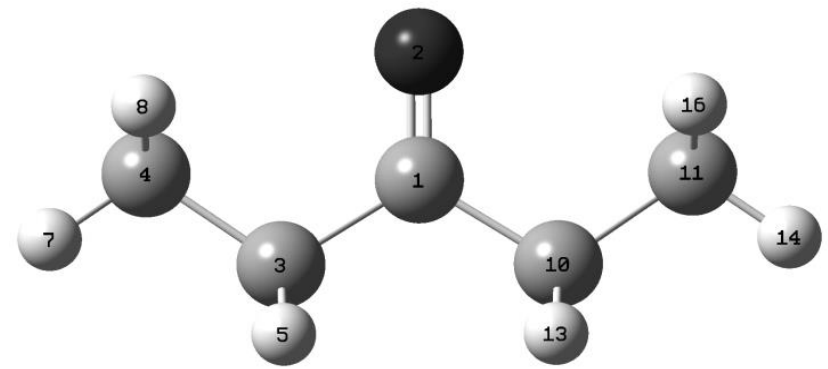

Figure 2. Geometry of the observed conformer of diethyl ketone.

initial assumption, the optimized structure was lacking a symmetry plane and a $\mathrm{C}_{2}$ symmetry instead of a $\mathrm{C}_{2 v}$ symmetry was obtained. Both ethyl groups were tilted against each other by an angle of approximately $24^{\circ}$. This result induced us to study the torsional behavior of the ethyl groups in more detail and we calculated a two-dimensional energy surface as a function of the torsional angles $\varphi_{1}=\angle\left(\mathrm{O}_{2}, \mathrm{C}_{1}, \mathrm{C}_{3}, \mathrm{C}_{4}\right)$ and $\varphi_{2}=\angle\left(\mathrm{O}_{2}, \mathrm{C}_{1}, \mathrm{C}_{10}, \mathrm{C}_{11}\right)$. For the atom numbers see Figure 2. To define the dihedral angle $\varphi=\angle(A, B, C, D)$ we look from $C$ along the $C B$ bond onto $B$. If $B C D$ spans the same plane as $A B C, \varphi$ is zero. If the BCD plane is rotated counterclockwise against the $A B C$ plane, $\varphi$ is positive, for a clockwise rotation of the BCD plane against the ABC plane, $\varphi$ is negative. With this definition, the geometries represented by $\left(\varphi_{1}\right.$, $\left.\varphi_{2}\right),\left(-\varphi_{1},-\varphi_{2}\right),\left(\varphi_{2}, \varphi_{1}\right)$, and $\left(-\varphi_{2},-\varphi_{1}\right)$ have the same potential energy. We optimized the geometry with $\varphi_{1}$ and $\varphi_{2}$ fixed at certain values in a grid of $10^{\circ}$. The corresponding energies were parametrized with a two-dimensional Fourier expansion based on terms, conforming to the correct symmetry of the angles $\varphi_{1}, \varphi_{2}$. The corresponding coefficients are reported in Table S2 in the supplementary material. Finally, using the Fourier coefficients the energy surface was drawn as a contour plot given in Figure 3 . It is obvious, that in the region centered at $\varphi_{1}=0^{\circ}, \varphi_{2}=0^{\circ}$ a broad energy minimum exists. To study this in detail, a one-dimensional energy plot along the diagonal from $\varphi_{1}=-180^{\circ}, \varphi_{2}=-180^{\circ}$ to $\varphi_{1}=180^{\circ}, \varphi_{2}=180^{\circ}$ was calculated (Figure 4). Also here it can be recognized that the potential is very flat in the range $\varphi_{1}=\varphi_{2}=-20^{\circ}$ to $+20^{\circ}$. We recalculated this region within a grid of $1^{\circ}$ and also plotted the result in Figure 4 with an enlarged scale. Clearly two minima are found at $\varphi_{1}=\varphi_{2} \approx-12$ and $+12^{\circ}$, which correspond to the fully optimized structure at the MP2/6-311++G(d,p) level of theory. The local maximum at $\varphi_{1}=\varphi_{2}=0^{\circ}$ is only $0.3 \mathrm{~kJ} / \mathrm{mol}$ above these minima. We also show an energy plot along the diagonal starting from $\varphi_{1}=-180^{\circ}, \varphi_{2}=180^{\circ}$ to $\varphi_{1}=180^{\circ}, \varphi_{2}=-180^{\circ}$. Here, a narrow minimum exists (Figure 5). We repeated the optimization using density functional theory at the restricted B3LYPI6-311++G(d,p) level. Here, we found indeed a $\mathrm{C}_{2 v}$ symmetry. For comparison, we also repeated the calculation of a complete two-dimensional energy surface at this level of theory (Figure 6) and two one- 


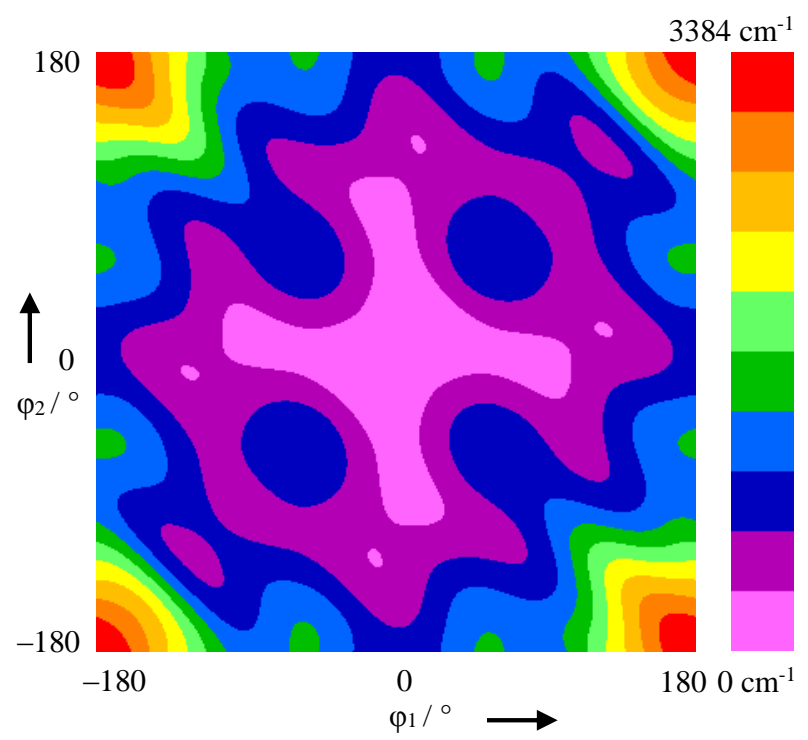

Figure 3. The potential surface of diethyl ketone obtained by rotating both ethyl groups calculated at the MP2/6-311++G(d,p) level of theory.

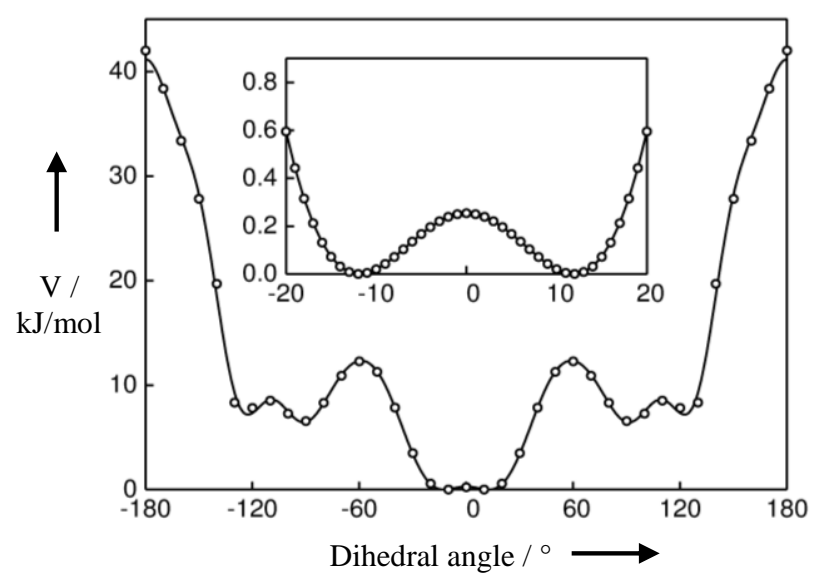

Figure 4. The potential curve along the diagonal shown in Figure 3 from $\varphi_{1}=\varphi_{2}=-180^{\circ}$ to $\varphi_{1}=\varphi_{2}=180^{\circ}$.

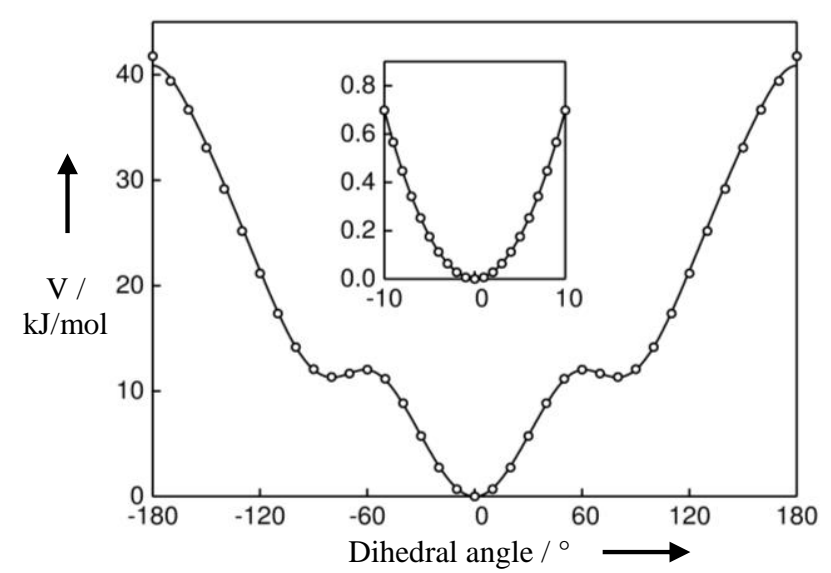

Figure 5. The potential curve along the diagonal shown in Figure 3 from $\left(\varphi_{1}, \varphi_{2}\right)=\left(-180^{\circ}, 180^{\circ}\right)$ to $\left(\varphi_{1}, \varphi_{2}\right)=\left(180^{\circ},-180^{\circ}\right)$.

dimensional energy plots along the same diagonals (Figure 7 and Figure 8). The corresponding coefficients are reported in Table S3. In Figure 7, a broad energy minimum is found around $\varphi_{1}=\varphi_{2}=0^{\circ}$, whereas the minima at $\varphi_{1}=\varphi_{2} \approx \pm 12^{\circ}$ do not occur.

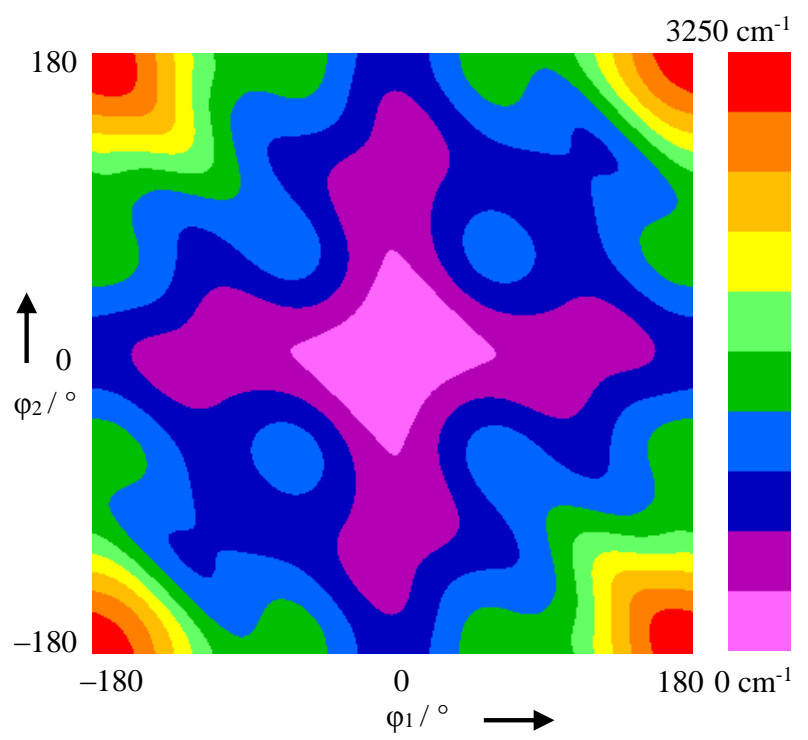

Figure 6. The potential surface of diethyl ketone obtained by rotating both ethyl groups calculated at the B3LYP/6-311++G(d,p) level of theory.

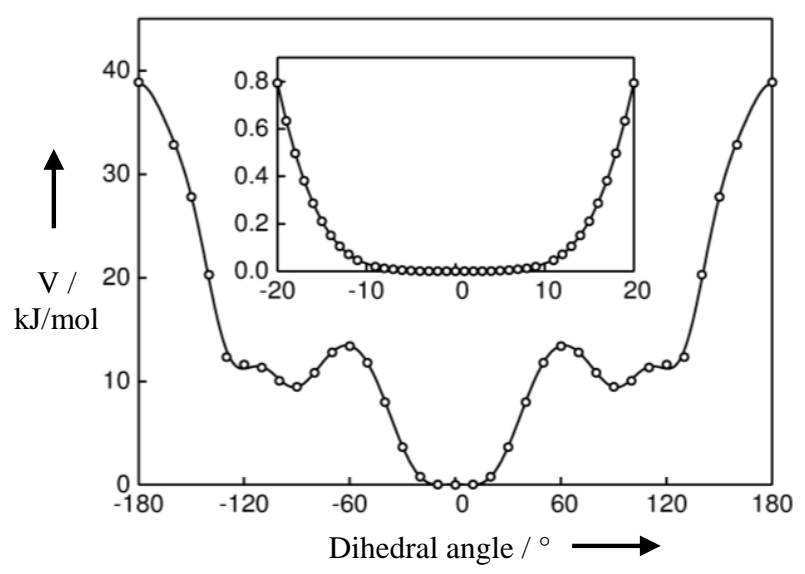

Figure 7. The potential curve along the diagonal shown in Figure 6 from $\varphi_{1}=\varphi_{2}=-180^{\circ}$ to $\varphi_{1}=\varphi_{2}=180^{\circ}$

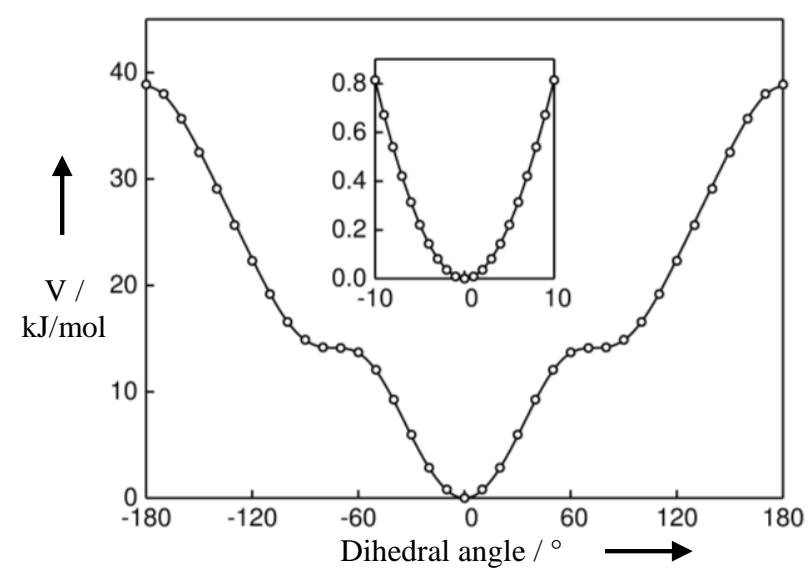

Figure 8. The potential curve along the diagonal shown in Figure 6 from $\left(\varphi_{1}, \varphi_{2}\right)=\left(-180^{\circ}, 180^{\circ}\right)$ to $\left(\varphi_{1}, \varphi_{2}\right)=\left(180^{\circ},-180^{\circ}\right)$.

Finally, we calculated a potential energy curve for the rotation of the methyl groups, since these caused splittings of the rotational lines and the three-fold hindering potential $V_{3}$ could be determined from the experimental data. Here, we also used the 
MP2/6-311++G(d,p) level of theory. In order to obtain a symmetry plane, the dihedral angles $\varphi_{1}$ and $\varphi_{2}$ were set to $0^{\circ}$. The dihedral angle $\alpha=\angle\left(\mathrm{C}_{1}, \mathrm{C}_{10}, \mathrm{C}_{11}, \mathrm{H}_{14}\right)$, which determines the rotation angle of one of the methyl groups was also fixed, whereas all other parameters were allowed to relaxe. Calculations were carried out at different angles $\alpha$ within a grid of $10^{\circ}$ and the data were parametrized with an expansion $\mathrm{V}=\mathrm{V}_{0}+\left(\mathrm{V}_{3} / 2\right)(\cos 3 \alpha)+\left(\mathrm{V}_{6} / 2\right)(\cos 6 \alpha)$. The offset $\mathrm{V}_{0}$ was determined to be -271.045845 Hartree, $\mathrm{V}_{3}$ is $10.90 \mathrm{~kJ} / \mathrm{mol}$ $\left(911.3 \mathrm{~cm}^{-1}\right), V_{6}$ is $0.073 \mathrm{~kJ} / \mathrm{mol}\left(6.1 \mathrm{~cm}^{-1}\right)$. The $V_{6}$ contribution to the three-fold $V_{3}$ potential is less than $1 \%$.

\section{Spectral assignment}

We will start this section with some remarks on the rotorsional symmetry labels used throughout this paper. The rotorsional states of an asymmetric molecule with two non-equivalent internal rotors can be classified within the direct product group $\mathrm{C}_{3}{ }^{(1)} \otimes \mathrm{C}_{3}{ }^{(2)}$, where the subgroups $\mathrm{C}_{3}{ }^{(1)}$ and $\mathrm{C}_{3}{ }^{(2)}$ refer to the symmetry of the torsional wave functions of the first and the second internal rotor, respectively. ${ }^{[16]}$ The symmetry species of the rotorsional states are $A A,\left[E_{a} E_{a}+E_{b} E_{b}\right]=E E,\left[E_{a} E_{b}+E_{b} E_{a}\right]=E E^{*},\left[E_{a} A+E_{b} A\right]=E A$, $\left[A E_{a}+A E_{b}\right]=A E$. For convenience we introduced the abbreviated symmetry labels $A A, E E, E E^{*}, E A$, and $A E$. These labels can still be used in the case of diethyl ketone, in which the two internal rotors are equivalent due to the $\mathrm{C}_{2}$ or $\mathrm{C}_{2 v}$ symmetry of the molecular frame. However, it has to be considered, that the EA states coincide with the AE states. Therefore, we will consistently use the label $A E$.

At the beginning of our experimental studies a broadband scan with the spectrometer described in ${ }^{[12]}$ in the frequency range from 31.4 GHz to $36.0 \mathrm{GHz}$ was recorded. Only 20 lines were found. In a first step, a prediction of the AA components with a rigid rotor program was carried out starting with the calculated rotational constants of the planar conformer obtained at the MP2 level. By comparing the observed and the predicted spectra, all 20 transitions could be assigned and three rotational constants were determined with a standard deviation of $467 \mathrm{kHz}$. This is in the same order as the resolution of the spectrometer when it is used in the scan mode. It should be mentioned that only $b$-type transitions could be observed. The centrifugal distortion constants were not fitted because the resolution in the scan mode is in the order of about $500 \mathrm{kHz}$, much larger than the order of the centrifugal distortion constants. In the range from $31.4 \mathrm{GHz}$ to 36.0 GHz no measurements in the high resolution mode were carried out, since the lines turned out too weak for an analysis of their torsional fine structure. However, the observed transitions and the preliminary rotational constants obtained from the fit are given as supplementary data in Table S4.
We used these preliminary rotational constants to predict the spectrum of the AA species lines of diethyl ketone in the frequency range from $5 \mathrm{GHz}$ to $26.5 \mathrm{GHz}$ and measured the predicted transitions directly in the high resolution mode with the spectrometer described in [11]. Almost all lines turned out to be multiplets. Some lines (also that one presented in Figure 1) appeared clearly as AA, AE, EE, and $E^{*}$ quartets. Many lines appeared just as triplets due to a very small splitting between the $E E$ and the $E^{*}$ species (in some cases lower than $1 \mathrm{kHz}$ ) and could not be resolved even in the high resolution mode.

For the analysis of the torsional fine structure a complete spectrum with all torsional components was predicted using the xiam code. ${ }^{[17]}$ In a first step, we assumed the barrier of both methyl groups to be approximately $800 \mathrm{~cm}^{-1}$, similar to the barrier of the $\mathrm{CH}_{3}-\mathrm{CH}_{2}-\mathrm{CO}$ methyl group in methyl ethyl ketone. ${ }^{[4]}$ The splittings between the different symmetry species of the observed and calculated spectra matched almost exactly. We could assign all lines of the four species on the basis of these splittings. Totally, 54 transitions with 199 torsional components were fitted using the xiam code to a standard deviation of only $3.9 \mathrm{kHz}$. It should be noted that most of the lines have a line width of about $20 \mathrm{kHz}$, much larger than the line width of $2 \mathrm{kHz}$ at $12 \mathrm{GHz}$ observed for the 1-0 transition of carbonyl sulfide. ${ }^{[18]}$ Also in other compounds additionally broadened lines were found, e.g. the line width was $12 \mathrm{kHz}$ in the cases of allyl acetate [19] and ethyl acetate. ${ }^{[20]}$ However, in the case of the title compound an even bigger broadening was observed. Moreover, many lines, even strong lines, have additional narrow splittings, which we attribute to magnetic coupling effects of the 10 protons present in the molecule. However, small splittings could also arise from the double minimum potential calculated on the MP2/6-311++G(d,p) level (see Figure 4). Due to the broadened lines, the line positions could be determined only with an accuracy of about $4 \mathrm{kHz}$, which is by a factor of 2 worse than the accuracy of $2 \mathrm{kHz}$ which we achieved in the cases of allyl acetate ${ }^{[19]}$ and ethyl acetate. ${ }^{[20]}$ However, using the program xiam, all lines could be fitted within experimental accuracy.

The fitted molecular parameters are shown in Table 1. A frequency list of all transitions with their torsional components is available as supplementary material (Table S1).

\section{Results and Discussion}

We measured and assigned the rotational spectrum of diethyl ketone. From the experimental data we determined the rotational and centrifugal distortion constants, as well as the torsional constants of the methyl groups. The experimental constants were compared to those obtained by ab initio methods. Moreover, two- 


\begin{tabular}{|c|c|c|c|c|c|c|c|c|}
\hline parameter & unit & $\begin{array}{l}\text { Observed } \\
\text { (xiam) }\end{array}$ & $\begin{array}{c}\text { MP2 } \\
\left(\varphi_{1}=\varphi_{2}=0^{\circ}\right)\end{array}$ & $\begin{array}{c}\text { obs-MP2 } \\
\left(\varphi_{1}=\varphi_{2}=0^{\circ}\right)\end{array}$ & $\begin{array}{c}\text { MP2 } \\
\text { optimized }\end{array}$ & $\begin{array}{l}\text { obs-MP2 } \\
\text { optimized }\end{array}$ & DFT & obs-DFT \\
\hline$A$ & $\mathrm{GHz}$ & $8.89243817(17)$ & 8.876 & 0.016 & 8.816 & 0.076 & 8.937 & -0.045 \\
\hline C & $\mathrm{GHz}$ & $1.67014354(12)$ & 1.669 & 0.001 & 1.672 & -0.002 & 1.653 & 0.017 \\
\hline$\Delta\lrcorner$ & $\mathrm{kHz}$ & $0.17346(26)$ & & & & & & \\
\hline$\Delta \mathrm{JK}$ & $\mathrm{kHz}$ & $0.5955(44)$ & & & & & & \\
\hline$\Delta \mathrm{K}$ & $\mathrm{kHz}$ & $3.9704(86)$ & & & & & & \\
\hline$\delta_{\mathrm{K}}$ & $\mathrm{kHz}$ & $0.125(17)$ & & & & & & \\
\hline \multirow[t]{3}{*}{$\mathrm{V}_{3}$} & $\mathrm{GHz}$ & $23141.8(79)$ & & & & & & \\
\hline & $\mathrm{kJ} / \mathrm{mol}$ & $9.2343(32)$ & & & & & & \\
\hline & $\mathrm{cm}^{-1}$ & $771.93(27)$ & 911 & -139 & & & & \\
\hline$I_{\gamma}$ & $u \AA^{2}$ & 3.1586 (fixed) & & & & & & \\
\hline$\angle(\mathrm{i}, \mathrm{a})$ & $\circ$ & $34.12(13)$ & 34.77 & -0.65 & 34.32 & -0.20 & 33.95 & 0.17 \\
\hline$\angle(\mathrm{i}, \mathrm{b})$ & $\circ$ & $55.88(13)$ & 55.23 & 0.65 & 56.48 & -0.60 & 56.05 & -0.37 \\
\hline$\angle(\mathrm{i}, \mathrm{c})$ & $\circ$ & 90.00 (fixed) & 90.00 & 0.00 & 96.56 & -6.56 & 89.95 & 0.05 \\
\hline$P_{c c}=I_{a}+I_{b}-I_{c}$ & $\begin{array}{l}\mathrm{uA}{ }^{2} \\
\mathrm{kHz}\end{array}$ & $\begin{array}{l}12.849 \\
3.5\end{array}$ & 12.507 & 0.342 & 13.439 & -0.590 & 12.262 & 0.587 \\
\hline $\mathrm{N}_{\text {tot }}$ & & 199 & & & & & & \\
\hline
\end{tabular}

ethyl groups and a potential curve for the rotation of the methyl groups were calculated by theoretical methods.

An fully optimized ab initio geometry calculated at the MP2/6$311++G(d, p)$ level of theory yielded a geometry without a mirror plane. The A rotational constant was found to be $76 \mathrm{MHz}$ too small if compared to the experimental value, whereas the $B$ and the $\mathrm{C}$ constant agreed within $2 \mathrm{MHz}$. The observed planar moment $P_{c c}=I_{a}+I_{b}-I_{c}$ is $0.590 u \AA^{2}$ smaller than the calculated value. This is quite unusual, since due to out-of-plane vibrations the experimental planar moment is expected to be bigger than the calculated one. If the same MP2 calculation is carried out with $\varphi_{1}=\varphi_{2}=0^{\circ}$ as a constraint, a geometry with an ab mirror plane is obtained and the agreement between observed and calculated rotational constants has significantly improved. In this case the $A$ constant is only $16 \mathrm{MHz}$ too small, and $B$ and $C$ still agree within $2 \mathrm{MHz}$. Now the experimental planar moment $\mathrm{P}_{\mathrm{cc}}$ is $0.342 \mathrm{u} \AA^{2}$ bigger than the calculated value, which is reasonable considering strong out-of-plane torsions of the ethyl groups. Finally, a DFT calculation carried out at the B3LYP/6-311++G(d,p) level without any constraint yielded also a geometry with an $a b$ mirror plane. Here, the agreement between the observed and calculated rotational constants was worse than for the MP2 calculation using the $\varphi_{1}=\varphi_{2}=0^{\circ}$ constraint, however, the observed planar moment turned out to be $0.587 \mathrm{u} \AA^{2}$ bigger than the calculated one, which is still a reasonable deviation. Obviously, the experimental rotational constants are in better agreement with a $\mathrm{C}_{2 v}$ geometry containing a mirror plane rather than a $\mathrm{C}_{2}$ structure without a symmetry plane. For both, $\mathrm{a}_{2 v}$ and $a \mathrm{C}_{2}$ geometry the dipole moment vector is in $b$ direction. Therefore, the absence of $a$ - and $c$-type transitions does not rule out the existence of an $a b$ mirror plane.

The two-dimensional potential surface calculated on MP2 (Figure 3) and on DFT level (Figure 6), predict a very broad energy diagrams along the $\varphi_{1}=\varphi_{2}$ diagonals are considered it is found, that in the case of the MP2 calculation (Figure 4) a double minimum potential with a local maximum at $\varphi_{1}=\varphi_{2}=0^{\circ}$ and two minima at $\varphi_{1}=\varphi_{2} \approx \pm 12^{\circ}$ exist. These minima correspond to the $C_{2}$ geometry found after optimizing all structure parameters at the MP2 level. Sample calculations using a simple rotator-on-an-arc model with an arc of $\Delta \varphi= \pm 10^{\circ}$ and the rotor being one ethyl group rotating against a rigid frame have shown, that the lowest torsional energy level is above the local energy maximum of approximately $0.3 \mathrm{~kJ} / \mathrm{mol}$. Therefore, the lowest torsional wave function and accordingly, the corresponding probability density has a maximum at $\varphi_{1}=\varphi_{2}=0^{\circ}$. Therefore, the effective structure might be $\mathrm{C}_{2 v}$. In contrast to the MP2 $\varphi_{1}=\varphi_{2}$ diagonal, the DFT calculations (Figure 7) show a simple global minimum at $\varphi_{1}=\varphi_{2}=0^{\circ}$ resulting directly in a $\mathrm{C}_{2 v}$ geometry of the diethyl ketone molecule. However, it should be mentioned that also here the minimum is extremely broad covering a range of $\Delta \varphi= \pm 10^{\circ}$.

Internal rotation of two equivalent methyl groups gave rise to a quartet structure of all rotational transitions. The torsional parameters were fitted to give $\mathrm{a}_{3}$ potential of $771.93(27) \mathrm{cm}^{-1}$ and an angle between the internal rotor axis and the $a$ axis of $\angle(\mathrm{i}, \mathrm{a})=34.12(13)^{\circ}$. The $\mathrm{V}_{3}$ potential is very similar to the barrier hight of $795(10) \mathrm{cm}^{-1}$ reported for methyl ethyl ketone, but it is $18 \%$ lower than the value of $911.3 \mathrm{~cm}^{-1}$ predicted by ab initio calculations carried out at the MP2 level of theory. The angle $\angle(\mathrm{i}, \mathrm{a})$ is in excellent agreement with the angle of $34.77^{\circ}$ calculated with the MP2 method using the $\varphi_{1}=\varphi_{2}=0^{\circ}$ constraint. Both potential curves (Figure 4 and Figure 7) show local minima at approximately $\varphi_{1}=\varphi_{2}=90^{\circ}$. Therefore at least one other conformer might exist. Checking these point with harmonic frequency calculations at the MP2/6-311++G(d,p) level have shown that they are saddle points rather than local minima. Even if they would represent another stable conformer it would be 
approximately $8 \mathrm{~kJ} / \mathrm{mol}$ above the $\varphi_{1}=\varphi_{2}=0^{\circ}$ conformer and therefore unlikely to be observed under molecular beam conditions. This existence of only one conformer is also supported by the fact that almost all observed lines were assigned to the $\varphi_{1}=\varphi_{2}=0^{\circ}$ conformer and only a very few weak lines remained unassigned.

\section{Conclusion}

The microwave spectrum of diethyl ketone has been analyzed in terms of rotational constants, centrifugal distortion constants, and constants of methyl internal rotation. By combining these results with quantum chemical calculations it has been deduced the diethyl ketone has an effective structure with $\mathrm{C}_{2 v}$ symmetry. Whether this effective structure corresponds to $\mathrm{a}_{2 v}$ or a $\mathrm{C}_{2}$ equilibrium geometry is still uncertain. This might become a subject of future studies with more advanced quantum chemical methods. However, the potential for the bending motions of the ethyl group out of the mirror plane turned out to be extraordinarily broad. The barrier to internal rotation of the methyl groups were found to be in good agreement with the barrier reported for the $\mathrm{CH}_{3}-\mathrm{CH}_{2}-\mathrm{CO}$ methyl group of methyl ethyl ketone.

\section{Acknowledgements}

We thank the Center for Computing and Communication of the RWTH Aachen University for free computer time and the Land Nordrhein-Westfalen for funds. Furthermore, we thank Gergana Tsvetanova Ivanova for her contribution within a student research project.

Keywords: rotational spectrum - microwave spectroscopy diethyl ketone $\cdot$ internal rotation

[1] J. D. Swalen and C. C. Costain, J. Chem. Phys. 1959, 31, 1562-1574.

[2] R. Peter, H. Dreizler, Z. Naturforsch. 1965, 204, 301-312.

[3] L. Evangelisti, L. B. Favero, A. Maris, S. Melandri, A. Vega-Toribio, A. Lesarri, W. Caminati, J. Mol. Spec. 2010, 259, 65-69.

[4] N. M. Pozdeev, A. K. Mamleev, L. N. Gunderova, R. V. Galeev, J. Struc. Chem. 1988, 29, 52-58.

[5] A. C. Fantoni, W. Caminati, R. Meyer, Chem. Phys. Lett. 1987, 133, 2733.

[6] W. Caminati and J.-U. Grabow, J. Am. Chem. Soc. 2006, 128, 854-857

[7] M. Onda, Y. Kohama, K. Suga, I. Yamaguchi, J. Mol. Str. 1998, 442, $19-$ 22.
[8] M. J. Tubergen, R. J. Lavrich, D. F. Plusquellic, R. D. Suenram, J. Phys. Chem. A 2006, 110, 13188-13194.

[9] A. Maris, S. Melandri, W. Caminati, P. G. Favero, Chem. Phys. Lett. 1996, 256, 509-512.

[10] S. Blanco, J. C. Lopez, A. B. Gomez, J. L. Alonso, Mol. Phys. 1999, 97, 853-858.

[11] J.-U. Grabow, W. Stahl, H. Dreizler, Rev. Sci. Instrum. 1996, 67, $4072-$ 4084 .

[12] I. Merke, W. Stahl, H. Dreizler, Z. Naturforsch. 1994, 49a, 490-496.

[13] Gaussian 03, Revision D.02, M. J. Frisch, G. W. Trucks, H. B. Schlegel, G. E. Scuseria, M. A. Robb, J. R. Cheeseman, J. A. Montgomery, Jr., T. Vreven, K. N. Kudin, J. C. Burant, J. M. Millam, S. S. lyengar, J. Tomasi, V. Barone, B. Mennucci, M. Cossi, G. Scalmani, N. Rega, G. A. Petersson, H. Nakatsuji, M. Hada, M. Ehara, K. Toyota, R. Fukuda, J. Hasegawa, M. Ishida, T. Nakajima, Y. Honda, O. Kitao, H. Nakai, M. Klene, X. Li, J. E. Knox, H. P. Hratchian, J. B. Cross, V. Bakken, C. Adamo, J. Jaramillo, R. Gomperts, R. E. Stratmann, O. Yazyev, A. J. Austin, R. Cammi, C. Pomelli, J. W. Ochterski, P. Y. Ayala, K. Morokuma, G. A. Voth, P. Salvador, J. J. Dannenberg, V. G. Zakrzewski, S. Dapprich, A. D. Daniels, M. C. Strain, O. Farkas, D. K. Malick, A. D. Rabuck, K. Raghavachari, J. B. Foresman, J. V. Ortiz, Q. Cui, A. G. Baboul, S. Clifford, J. Cioslowski, B. B. Stefanov, G. Liu, A. Liashenko, P. Piskorz, I. Komaromi, R. L. Martin, D. J. Fox, T. Keith, M. A. Al-Laham, C. Y. Peng, A. Nanayakkara, M. Challacombe, P. M. W. Gill, B. Johnson, W. Chen, M. W. Wong, C. Gonzalez, and J. A. Pople, Gaussian, Inc., Wallingford CT, 2004.

[14] H. V. L. Nguyen and W. Stahl, J. Mol. Spectrosc. 2010, 264, 120-124.

[15] H. Mouhib, Y. Zhao, and W. Stahl, J. Mol. Spectrosc. 2010, 261, 59-62.

[16] H. Dreizler, Z. Naturforsch. 1961, 16a, 1354-1367.

[17] H. Hartwig, H. Dreizler, Z. Naturforsch. 1996, 51a, 923-932.

[18] J.-U. Grabow, W. Stahl, Z. Naturforsch. 1990, 45a, 1043-1044.

[19] H. V. L. Nguyen, H. Mouhib, W. Stahl, I. Kleiner, Mol. Phys. 2010, 108, 763-770.

[20] D. Jelisavac, D. Cortés Gómez, H. V. L. Nguyen, L.W. Sutikdja, W. Stahl, I. Kleiner, J. Mol. Spectrosc. 2009, 257, 111-115.
Received: ((will be filled in by the editorial staff)) Published online: ((will be filled in by the editorial staff)) 
Entry for the Table of Contents (Please choose one layout)

Layout 1:

\section{THE ROTATIONAL SPECTRUM OF DIETHYL KETONE}

\begin{abstract}
The rotational spectrum of diethyl ketone was observed by Fourier transform microwave spectroscopy under molecular beam conditions. In a global analysis using the xiam code rotational constants, centrifugal distortion constants, and the torsional barrier of the methyl groups were determined. The experimental work was supplemented by quantum chemical calculations. Combining the experimental and theoretical results, an effective structure with $\mathrm{C}_{2 \mathrm{v}}$ symmetry was found.
\end{abstract}

H.V.L. Nguyen*, W. Stahl

Page No. - Page No.

The rotational spectrum of diethyl ketone 


\section{Supplementary data}

\section{The Rotational Spectrum of Diethyl Ketone}

H.V.L. Nguyen and W. Stahl

Institute of Physical Chemistry, RWTH Aachen University, Landoltweg 2, D-52074 Aachen, Germany 
TABLE S1: Observed AA, AE, EE and EE* species frequencies (obs) of diethyl ketone. Observed calculated values as obtained after a fit with xiam.

\begin{tabular}{|c|c|c|c|c|c|c|c|c|}
\hline \multicolumn{3}{|c|}{$\begin{array}{l}\mathbf{J} \underset{\mathbf{a}}{\mathbf{K}} \mathbf{K}_{\mathbf{a}} \mathbf{K}_{\mathbf{c}} \\
\text { uppr level }\end{array}$} & \multicolumn{4}{|c|}{ 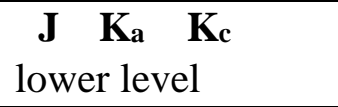 } & \multirow{2}{*}{$\begin{array}{c}\begin{array}{c}\text { obs } \\
\mathrm{GHz}\end{array} \\
10.5626611\end{array}$} & \multirow{2}{*}{$\begin{array}{c}\text { obs-calc } \\
\mathrm{kHz} \\
-2.7\end{array}$} \\
\hline \multirow[t]{4}{*}{1} & 1 & 1 & 0 & 0 & 0 & $\mathrm{AA}$ & & \\
\hline & & & & & & $\mathrm{AE}$ & 10.5626240 & -1.4 \\
\hline & & & & & & $\mathrm{EE}$ & 10.5625879 & 2.3 \\
\hline & & & & & & $\mathrm{EE}^{*}$ & 10.5625879 & -0.5 \\
\hline \multirow[t]{4}{*}{1} & 1 & 0 & 1 & 0 & 1 & $\mathrm{AA}$ & 7.2223052 & 3.2 \\
\hline & & & & & & $\mathrm{AE}$ & 7.2222687 & 3.7 \\
\hline & & & & & & $\mathrm{EE}$ & 7.2222299 & 0.4 \\
\hline & & & & & & $\mathrm{EE}^{*}$ & 7.2222299 & 3.3 \\
\hline \multirow[t]{4}{*}{2} & 1 & 2 & 1 & 0 & 1 & $\mathrm{AA}$ & 13.9030136 & -6.1 \\
\hline & & & & & & $\mathrm{AE}$ & 13.9029783 & -3.5 \\
\hline & & & & & & $\mathrm{EE}$ & 13.9029417 & -1.7 \\
\hline & & & & & & $\mathrm{EE}^{*}$ & 13.9029417 & -2.6 \\
\hline \multirow[t]{4}{*}{2} & 1 & 1 & 2 & 0 & 2 & $\mathrm{AA}$ & 7.5148153 & -2.7 \\
\hline & & & & & & $\mathrm{AE}$ & 7.5147816 & 1.9 \\
\hline & & & & & & $\mathrm{EE}$ & 7.5147468 & 4.9 \\
\hline & & & & & & $\mathrm{EE}^{*}$ & 7.5147468 & 5.8 \\
\hline \multirow[t]{4}{*}{2} & 2 & 1 & 2 & 1 & 2 & $\mathrm{AA}$ & 21.6668614 & 11.3 \\
\hline & & & & & & $\mathrm{AE}$ & 21.6666480 & 3.8 \\
\hline & & & & & & $\mathrm{EE}$ & 21.6662637 & 0.5 \\
\hline & & & & & & $\mathrm{EE}^{*}$ & 21.6666194 & -5.3 \\
\hline \multirow[t]{2}{*}{2} & 2 & 0 & 2 & 1 & 1 & $\mathrm{EE}$ & 20.8235884 & -6.3 \\
\hline & & & & & & $\mathrm{EE}^{*}$ & 20.8232280 & -5.2 \\
\hline \multirow[t]{4}{*}{3} & 1 & 3 & 2 & 0 & 2 & $\mathrm{AA}$ & 17.1046482 & -10.5 \\
\hline & & & & & & $\mathrm{AE}$ & 17.1046178 & -3.5 \\
\hline & & & & & & $\mathrm{EE}$ & 17.1045821 & -1.6 \\
\hline & & & & & & $\mathrm{EE}^{*}$ & 17.1045821 & -2.1 \\
\hline \multirow[t]{4}{*}{3} & 2 & 1 & 3 & 1 & 2 & $\mathrm{AA}$ & 20.4370037 & -0.5 \\
\hline & & & & & & $\mathrm{AE}$ & 20.4369109 & -3.1 \\
\hline & & & & & & $\mathrm{EE}$ & 20.4368619 & 0.6 \\
\hline & & & & & & $\mathrm{EE}^{*}$ & 20.4367900 & 3.7 \\
\hline \multirow[t]{4}{*}{4} & 0 & 4 & 3 & 1 & 3 & $\mathrm{AA}$ & 8.1466328 & 5.5 \\
\hline & & & & & & $\mathrm{AE}$ & 8.1466489 & -9.9 \\
\hline & & & & & & $\mathrm{EE}$ & 8.1466900 & -0.7 \\
\hline & & & & & & $\mathrm{EE}^{*}$ & 8.1466900 & -0.2 \\
\hline \multirow[t]{4}{*}{4} & 1 & 4 & 3 & 0 & 3 & AA & 20.1785087 & -9.1 \\
\hline & & & & & & $\mathrm{AE}$ & 20.1784764 & -5.0 \\
\hline & & & & & & $\mathrm{EE}$ & 20.1784462 & 1.4 \\
\hline & & & & & & $\mathrm{EE}^{*}$ & 20.1784462 & 1.1 \\
\hline
\end{tabular}


TABLE S1: continued: Observed AA, AE, EE and EE* species frequencies (obs) of diethyl ketone. Observed - calculated values as obtained after a fit with xiam.

\begin{tabular}{|c|c|c|c|c|c|c|c|c|}
\hline \multicolumn{3}{|c|}{$\begin{array}{c}\mathbf{J} \mathbf{K}_{\mathbf{a}} \mathbf{K}_{\mathbf{c}} \\
\text { upper level }\end{array}$} & \multicolumn{3}{|c|}{$\underset{\text { lower level }}{\mathbf{J}} \mathbf{K}_{\mathbf{a}} \mathbf{K}_{\mathbf{c}}$} & & $\begin{array}{c}\text { obs } \\
\mathrm{GHz}\end{array}$ & \multirow{2}{*}{$\begin{array}{c}\begin{array}{c}\text { obs-calc } \\
\mathrm{kHz}\end{array} \\
-22\end{array}$} \\
\hline \multirow[t]{3}{*}{4} & 2 & 2 & 4 & 1 & 3 & AA & 19.9648948 & \\
\hline & & & & & & $\mathrm{AE}$ & 19.9647945 & -1.5 \\
\hline & & & & & & $\mathrm{EE}^{*}$ & 19.9646870 & 4.5 \\
\hline \multirow[t]{4}{*}{5} & 0 & 5 & 4 & 1 & 4 & $\mathrm{AA}$ & 12.1869861 & -3.2 \\
\hline & & & & & & $\mathrm{AE}$ & 12.1870257 & 7.3 \\
\hline & & & & & & $\mathrm{EE}$ & 12.1870505 & 2.8 \\
\hline & & & & & & $\mathrm{EE}^{*}$ & 12.1870505 & 3.1 \\
\hline \multirow[t]{4}{*}{5} & 1 & 4 & 5 & 0 & 5 & $\mathrm{AA}$ & 9.4441392 & 3.1 \\
\hline & & & & & & $\mathrm{AE}$ & 9.4440938 & 1.3 \\
\hline & & & & & & $\mathrm{EE}$ & 9.4440561 & 7.2 \\
\hline & & & & & & $\mathrm{EE}^{*}$ & 9.4440561 & 7.3 \\
\hline \multirow[t]{3}{*}{5} & 1 & 5 & 4 & 0 & 4 & $\mathrm{AE}$ & 23.1420602 & -4.3 \\
\hline & & & & & & $\mathrm{EE}$ & 23.1420278 & -1.4 \\
\hline & & & & & & $\mathrm{EE}^{*}$ & 23.1420278 & -1.6 \\
\hline \multirow[t]{4}{*}{5} & 2 & 3 & 5 & 1 & 4 & $\mathrm{AA}$ & 19.4435255 & -1.1 \\
\hline & & & & & & $\mathrm{AE}$ & 19.4434240 & 0.0 \\
\hline & & & & & & $\mathrm{EE}$ & 19.4433260 & -0.7 \\
\hline & & & & & & $\mathrm{EE}^{*}$ & 19.4433260 & 9.9 \\
\hline \multirow[t]{3}{*}{5} & 2 & 4 & 5 & 1 & 5 & $\mathrm{AE}$ & 23.4025056 & 5.2 \\
\hline & & & & & & $\mathrm{EE}$ & 23.4023716 & -3.2 \\
\hline & & & & & & $\mathrm{EE}^{*}$ & 23.4023921 & 6.7 \\
\hline \multirow[t]{2}{*}{5} & 3 & 2 & 6 & 2 & 5 & $\mathrm{AA}$ & 13.7734428 & -3.3 \\
\hline & & & & & & $\mathrm{EE}^{*}$ & 13.7730841 & -2.8 \\
\hline \multirow[t]{2}{*}{5} & 3 & 3 & 6 & 2 & 4 & $\mathrm{AA}$ & 13.1822798 & -1.5 \\
\hline & & & & & & $\mathrm{EE}^{*}$ & 13.1819219 & -1.0 \\
\hline \multirow[t]{4}{*}{6} & 0 & 6 & 5 & 1 & 5 & $\mathrm{AA}$ & 16.2662223 & 4.9 \\
\hline & & & & & & $\mathrm{AE}$ & 16.2662466 & 2.9 \\
\hline & & & & & & $\mathrm{EE}$ & 16.2662727 & 2.5 \\
\hline & & & & & & $\mathrm{EE}^{*}$ & 16.2662727 & 2.8 \\
\hline \multirow[t]{4}{*}{6} & 1 & 5 & 6 & 0 & 6 & $\mathrm{AA}$ & 10.5138487 & -4.4 \\
\hline & & & & & & $\mathrm{AE}$ & 10.5138061 & -0.7 \\
\hline & & & & & & $\mathrm{EE}$ & 10.5137661 & 5.6 \\
\hline & & & & & & $\mathrm{EE}^{*}$ & 10.5137661 & 5.7 \\
\hline \multirow[t]{4}{*}{6} & 2 & 4 & 6 & 1 & 5 & $\mathrm{AA}$ & 18.9166952 & 1.3 \\
\hline & & & & & & $\mathrm{AE}$ & 18.9165935 & 1.2 \\
\hline & & & & & & $\mathrm{EE}$ & 18.9164914 & -1.9 \\
\hline & & & & & & $\mathrm{EE}^{*}$ & 18.9164914 & 3.3 \\
\hline \multirow[t]{4}{*}{6} & 2 & 5 & 6 & 1 & 6 & AA & 24.2800517 & 0.0 \\
\hline & & & & & & $\mathrm{AE}$ & 24.2799344 & 4.2 \\
\hline & & & & & & $\mathrm{EE}$ & 24.2798129 & 6.8 \\
\hline & & & & & & $\mathrm{EE}^{*}$ & 24.2798129 & 1.5 \\
\hline
\end{tabular}


TABLE S1: continued: Observed AA, AE, EE and EE* species frequencies (obs) of diethyl ketone. Observed - calculated values as obtained after a fit with xiam.

\begin{tabular}{|c|c|c|c|c|c|c|c|c|}
\hline \multicolumn{3}{|c|}{$\begin{array}{c}\mathbf{J} \mathbf{K}_{\mathbf{a}} \mathbf{K}_{\mathbf{c}} \\
\text { upper level }\end{array}$} & \multicolumn{3}{|c|}{$\begin{array}{c}\mathbf{J} \quad \mathbf{K}_{\mathbf{a}} \quad \mathbf{K}_{\mathbf{c}} \\
\text { lower level }\end{array}$} & & $\begin{array}{c}\text { obs } \\
\mathrm{GHz} \\
\end{array}$ & \multirow{2}{*}{$\begin{array}{c}\text { obs-calc } \\
\mathrm{kHz} \\
-2.6\end{array}$} \\
\hline \multirow[t]{4}{*}{6} & 3 & 3 & 7 & 2 & 6 & AA & 10.2670098 & \\
\hline & & & & & & $\mathrm{AE}$ & 10.2669639 & -1.4 \\
\hline & & & & & & $\mathrm{EE}$ & 10.2671635 & -3.7 \\
\hline & & & & & & $\mathrm{EE}^{*}$ & 10.2666510 & -3.9 \\
\hline \multirow[t]{4}{*}{6} & 3 & 4 & 7 & 2 & 5 & $\mathrm{AA}$ & 9.2124080 & 0.4 \\
\hline & & & & & & $\mathrm{AE}$ & 9.2120982 & 0.1 \\
\hline & & & & & & $\mathrm{EE}$ & 9.2115388 & -0.7 \\
\hline & & & & & & $\mathrm{EE}^{*}$ & 9.2120518 & 0.0 \\
\hline \multirow[t]{4}{*}{7} & 0 & 7 & 6 & 1 & 6 & $\mathrm{AA}$ & 20.3515538 & 3.5 \\
\hline & & & & & & $\mathrm{AE}$ & 20.3515758 & 2.2 \\
\hline & & & & & & $\mathrm{EE}$ & 20.3515981 & 1.2 \\
\hline & & & & & & $\mathrm{EE}^{*}$ & 20.3515981 & 1.3 \\
\hline \multirow[t]{4}{*}{7} & 1 & 6 & 6 & 2 & 5 & $\mathrm{AA}$ & 7.9116209 & -3.9 \\
\hline & & & & & & $\mathrm{AE}$ & 7.9117183 & -1.6 \\
\hline & & & & & & $\mathrm{EE}$ & 7.9118178 & 0.0 \\
\hline & & & & & & $\mathrm{EE}^{*}$ & 7.9118178 & 5.5 \\
\hline \multirow[t]{4}{*}{7} & 1 & 6 & 7 & 0 & 7 & AA & 11.8401199 & -6.3 \\
\hline & & & & & & $\mathrm{AE}$ & 11.8400733 & -3.3 \\
\hline & & & & & & $\mathrm{EE}$ & 11.8400266 & -0.4 \\
\hline & & & & & & $\mathrm{EE}^{*}$ & 11.8400266 & -0.3 \\
\hline \multirow[t]{4}{*}{7} & 2 & 5 & 7 & 1 & 6 & AA & 18.4333419 & 0.8 \\
\hline & & & & & & $\mathrm{AE}$ & 18.4332438 & 2.3 \\
\hline & & & & & & $\mathrm{EE}$ & 18.4331450 & 1.6 \\
\hline & & & & & & $\mathrm{EE}^{*}$ & 18.4331450 & 4.5 \\
\hline \multirow[t]{2}{*}{7} & 4 & 3 & 8 & 3 & 6 & $\mathrm{AA}$ & 20.4279288 & -0.6 \\
\hline & & & & & & $\mathrm{EE}^{*}$ & 20.4274312 & -0.1 \\
\hline \multirow[t]{2}{*}{7} & 4 & 4 & 8 & 3 & 5 & $\mathrm{AA}$ & 20.3540660 & -0.8 \\
\hline & & & & & & $\mathrm{EE}^{*}$ & 20.3535687 & 0.2 \\
\hline \multirow[t]{4}{*}{8} & 1 & 7 & 7 & 2 & 6 & $\mathrm{AA}$ & 12.5466269 & -3.8 \\
\hline & & & & & & $\mathrm{AE}$ & 12.5467188 & -2.1 \\
\hline & & & & & & $\mathrm{EE}$ & 12.5468114 & -1.4 \\
\hline & & & & & & $\mathrm{EE}^{*}$ & 12.5468114 & 1.7 \\
\hline \multirow[t]{4}{*}{8} & 1 & 7 & 8 & 0 & 8 & $\mathrm{AA}$ & 13.4449660 & -8.2 \\
\hline & & & & & & $\mathrm{AE}$ & 13.4449177 & -3.0 \\
\hline & & & & & & $\mathrm{EE}$ & 13.4448677 & 0.6 \\
\hline & & & & & & $\mathrm{EE}^{*}$ & 13.4448677 & 0.6 \\
\hline \multirow[t]{4}{*}{8} & 2 & 6 & 8 & 1 & 7 & $\mathrm{AA}$ & 18.0444029 & 0.6 \\
\hline & & & & & & $\mathrm{AE}$ & 18.0443052 & 0.0 \\
\hline & & & & & & $\mathrm{EE}$ & 18.0442084 & -0.5 \\
\hline & & & & & & $\mathrm{EE}^{*}$ & 18.0442084 & 1.2 \\
\hline
\end{tabular}


TABLE S1: continued: Observed AA, AE, EE and EE* species frequencies (obs) of diethyl ketone. Observed - calculated values as obtained after a fit with xiam.

\begin{tabular}{|c|c|c|c|c|c|c|c|c|}
\hline \multicolumn{3}{|c|}{$\begin{array}{c}\mathbf{J} \mathbf{K}_{\mathbf{a}} \mathbf{K}_{\mathbf{c}} \\
\text { upper level }\end{array}$} & \multicolumn{3}{|c|}{$\underset{\text { lower level }}{\mathbf{J}} \mathbf{K}_{\mathbf{a}} \mathbf{K}$} & $\bar{K}_{\mathbf{c}}$ & \multirow{2}{*}{$\begin{array}{c}\begin{array}{c}\text { obs } \\
\mathrm{GHz}\end{array} \\
16.6092800\end{array}$} & \multirow{2}{*}{$\begin{array}{c}\begin{array}{c}\text { obs-calc } \\
\mathrm{kHz}\end{array} \\
2.5\end{array}$} \\
\hline 8 & 4 & 5 & 9 & 3 & 6 & AA & & \\
\hline & & & & & & $\mathrm{AE}$ & 16.6077737 & 0.2 \\
\hline & & & & & & $\mathrm{EE}^{*}$ & 16.6087806 & -0.6 \\
\hline \multirow[t]{3}{*}{8} & 4 & 4 & 9 & 3 & 7 & $\mathrm{AA}$ & 16.7565454 & 0.5 \\
\hline & & & & & & $\mathrm{AE}$ & 16.7575524 & -0.4 \\
\hline & & & & & & $\mathrm{EE}^{*}$ & 16.7560490 & 0.0 \\
\hline \multirow[t]{4}{*}{9} & 1 & 8 & 8 & 2 & 7 & $\mathrm{AA}$ & 17.2684168 & -0.9 \\
\hline & & & & & & $\mathrm{AE}$ & 17.2685038 & 0.8 \\
\hline & & & & & & $\mathrm{EE}$ & 17.2685855 & -3.8 \\
\hline & & & & & & $\mathrm{EE}^{*}$ & 17.2685855 & -1.9 \\
\hline \multirow[t]{4}{*}{9} & 2 & 7 & 9 & 1 & 8 & $\mathrm{AA}$ & 17.7993752 & 1.2 \\
\hline & & & & & & $\mathrm{AE}$ & 17.7992806 & 1.0 \\
\hline & & & & & & $\mathrm{EE}$ & 17.7991871 & 1.4 \\
\hline & & & & & & $\mathrm{EE}^{*}$ & 17.7991871 & 2.5 \\
\hline \multirow[t]{4}{*}{9} & 4 & 5 & 10 & 3 & 8 & $\mathrm{AA}$ & 13.0820864 & -1.1 \\
\hline & & & & & & $\mathrm{AE}$ & 13.0826230 & 3.2 \\
\hline & & & & & & $\mathrm{EE}$ & 13.0838711 & -1.5 \\
\hline & & & & & & $\mathrm{EE}^{*}$ & 13.0815948 & 0.7 \\
\hline \multirow[t]{4}{*}{9} & 4 & 6 & 10 & 3 & 7 & $\mathrm{AA}$ & 12.8099088 & 0.4 \\
\hline & & & & & & $\mathrm{AE}$ & 12.8088815 & -0.8 \\
\hline & & & & & & $\mathrm{EE}$ & 12.8071357 & 0.0 \\
\hline & & & & & & $\mathrm{EE}^{*}$ & 12.8094150 & 0.9 \\
\hline \multirow[t]{4}{*}{10} & 1 & 9 & 9 & 2 & 8 & $\mathrm{AA}$ & 22.0594216 & -6.9 \\
\hline & & & & & & $\mathrm{AE}$ & 22.0595062 & -2.3 \\
\hline & & & & & & $\mathrm{EE}$ & 22.0595885 & -0.7 \\
\hline & & & & & & $\mathrm{EE}^{*}$ & 22.0595885 & 0.5 \\
\hline \multirow[t]{4}{*}{10} & 2 & 8 & 10 & 1 & 9 & $\mathrm{AA}$ & 17.7435254 & 0.6 \\
\hline & & & & & & $\mathrm{AE}$ & 17.7434338 & 0.8 \\
\hline & & & & & & $\mathrm{EE}$ & 17.7433402 & -1.4 \\
\hline & & & & & & $\mathrm{EE}^{*}$ & 17.7433402 & -0.7 \\
\hline \multirow[t]{4}{*}{10} & 4 & 6 & 11 & 3 & 9 & $\mathrm{AA}$ & 9.4105200 & 0.4 \\
\hline & & & & & & $\mathrm{AE}$ & 9.4106677 & -0.1 \\
\hline & & & & & & $\mathrm{EE}$ & 9.4114273 & -0.8 \\
\hline & & & & & & $\mathrm{EE}^{*}$ & 9.4100284 & -0.4 \\
\hline \multirow[t]{4}{*}{10} & 4 & 7 & 11 & 3 & 8 & $\mathrm{AA}$ & 8.9375903 & -0.3 \\
\hline & & & & & & $\mathrm{AE}$ & 8.9369498 & -1.1 \\
\hline & & & & & & $\mathrm{EE}$ & 8.9356973 & -1.7 \\
\hline & & & & & & $\mathrm{EE}^{*}$ & 8.9370976 & -0.8 \\
\hline \multirow[t]{2}{*}{11} & 2 & 9 & 10 & 3 & 8 & $\mathrm{AA}$ & 8.3347970 & -0.8 \\
\hline & & & & & & $\mathrm{AE}$ & 8.3349727 & -1.1 \\
\hline
\end{tabular}


TABLE S1: continued: Observed AA, AE, EE and EE* species frequencies (obs) of diethyl ketone. Observed - calculated values as obtained after a fit with xiam.

\begin{tabular}{|c|c|c|c|c|c|c|c|c|}
\hline \multicolumn{3}{|c|}{$\begin{array}{c}\mathbf{J} \mathbf{K}_{\mathbf{a}} \mathbf{K}_{\mathbf{c}} \\
\text { upper level }\end{array}$} & \multicolumn{2}{|c|}{$\begin{array}{c}\mathbf{J} \quad \mathbf{K}_{\mathbf{a}} \\
\text { lower leve }\end{array}$} & \multicolumn{2}{|l|}{$\mathbf{K}_{\mathbf{c}}$} & \multirow{2}{*}{$\begin{array}{c}\text { obs } \\
\mathrm{GHz} \\
17.9164614\end{array}$} & \multirow{2}{*}{$\begin{array}{c}\text { obs-calc } \\
\mathrm{kHz} \\
-0.7\end{array}$} \\
\hline 11 & 2 & 9 & 11 & 1 & 10 & AA & & \\
\hline & & & & & & $\mathrm{AE}$ & 17.9163722 & -0.5 \\
\hline & & & & & & $\mathrm{EE}$ & 17.9162772 & -6.3 \\
\hline & & & & & & $\mathrm{EE}^{*}$ & 17.9162772 & -5.9 \\
\hline \multirow[t]{4}{*}{12} & 2 & 10 & 11 & 3 & 9 & AA & 13.1840171 & 3.7 \\
\hline & & & & & & $\mathrm{AE}$ & 13.1841836 & 0.7 \\
\hline & & & & & & $\mathrm{EE}$ & 13.1843620 & 1.9 \\
\hline & & & & & & $\mathrm{EE}^{*}$ & 13.1843377 & -7.3 \\
\hline \multirow[t]{4}{*}{12} & 2 & 10 & 12 & 1 & 11 & $\mathrm{AA}$ & 18.3520910 & 4.3 \\
\hline & & & & & & $\mathrm{AE}$ & 18.3520017 & 2.3 \\
\hline & & & & & & $\mathrm{EE}$ & 18.3519080 & -4.2 \\
\hline & & & & & & $\mathrm{EE}^{*}$ & 18.3519080 & -4.0 \\
\hline \multirow[t]{4}{*}{13} & 2 & 11 & 12 & 3 & 10 & $\mathrm{AA}$ & 18.2057938 & 5.9 \\
\hline & & & & & & $\mathrm{AE}$ & 18.2059545 & 2.9 \\
\hline & & & & & & $\mathrm{EE}$ & 18.2061157 & -4.3 \\
\hline & & & & & & $\mathrm{EE}^{*}$ & 18.2061157 & 4.8 \\
\hline \multirow[t]{4}{*}{13} & 2 & 12 & 12 & 3 & 9 & AA & 8.3807029 & 3.2 \\
\hline & & & & & & $\mathrm{AE}$ & 8.3808728 & 1.4 \\
\hline & & & & & & $\mathrm{EE}$ & 8.3810404 & 1.8 \\
\hline & & & & & & $\mathrm{EE}^{*}$ & 8.3810404 & -7.3 \\
\hline \multirow[t]{4}{*}{13} & 2 & 11 & 13 & 1 & 12 & AA & 19.0792351 & 0.0 \\
\hline & & & & & & $\mathrm{AE}$ & 19.0791485 & -0.9 \\
\hline & & & & & & $\mathrm{EE}$ & 19.0790623 & -1.5 \\
\hline & & & & & & $\mathrm{EE}^{*}$ & 19.0790623 & -1.4 \\
\hline \multirow[t]{4}{*}{14} & 2 & 13 & 13 & 3 & 10 & AA & 10.7653058 & -1.1 \\
\hline & & & & & & $\mathrm{AE}$ & 10.7654794 & 0.5 \\
\hline & & & & & & $\mathrm{EE}$ & 10.7656528 & 4.7 \\
\hline & & & & & & $\mathrm{EE}^{*}$ & 10.7656528 & -1.0 \\
\hline \multirow[t]{4}{*}{14} & 2 & 12 & 14 & 1 & 13 & AA & 20.1220183 & -1.0 \\
\hline & & & & & & $\mathrm{AE}$ & 20.1219340 & -0.6 \\
\hline & & & & & & $\mathrm{EE}$ & 20.1218528 & 2.8 \\
\hline & & & & & & $\mathrm{EE}^{*}$ & 20.1218528 & 3.0 \\
\hline \multirow[t]{4}{*}{14} & 5 & 9 & 15 & 4 & 12 & AA & 8.6936393 & 1.4 \\
\hline & & & & & & $\mathrm{AE}$ & 8.6944168 & 1.2 \\
\hline & & & & & & $\mathrm{EE}$ & 8.6960557 & 1.9 \\
\hline & & & & & & $\mathrm{EE}^{*}$ & 8.6930175 & -0.9 \\
\hline \multirow[t]{4}{*}{15} & 2 & 14 & 14 & 3 & 11 & $\mathrm{AA}$ & 12.8260643 & 2.3 \\
\hline & & & & & & $\mathrm{AE}$ & 12.8262337 & -0.4 \\
\hline & & & & & & $\mathrm{EE}$ & 12.8264042 & -0.2 \\
\hline & & & & & & $\mathrm{EE}^{*}$ & 12.8264042 & -3.9 \\
\hline
\end{tabular}


TABLE S2: Coefficients of the two-dimensional Fourier expansion for the energy potential surface calculated at the MP2/6-311++G(d,p) level of theory (Fig. 3).

\begin{tabular}{|c|c|c|}
\hline $\mathrm{Nr}$ & Coefficient & Value \\
\hline 1 & 1 & $-271.0437055(49)$ \\
\hline 2 & $\cos \left(\varphi_{1}\right)+\cos \left(\varphi_{2}\right)$ & $-0.0023296(48)$ \\
\hline 3 & $\cos \left(2 \varphi_{1}\right)+\cos \left(2 \varphi_{2}\right)$ & $0.0006021(48)$ \\
\hline 4 & $\cos \left(3 \varphi_{1}\right)+\cos \left(3 \varphi_{2}\right)$ & $-0.0009031(48)$ \\
\hline 5 & $\cos \left(4 \varphi_{1}\right)+\cos \left(4 \varphi_{2}\right)$ & $-0.0002170(48)$ \\
\hline 6 & $\cos \left(5 \varphi_{1}\right)+\cos \left(5 \varphi_{2}\right)$ & $-0.0000394(48)$ \\
\hline 7 & $\cos \left(6 \varphi_{1}\right)+\cos \left(6 \varphi_{2}\right)$ & $0.0000288(48)$ \\
\hline 8 & $\cos \left(\varphi_{1}\right) \cos \left(\varphi_{2}\right)$ & $0.0016448(94)$ \\
\hline 9 & $\sin \left(\varphi_{1}\right) \sin \left(\varphi_{2}\right)$ & $-0.0006171(101)$ \\
\hline 10 & $\cos \left(\varphi_{1}\right) \cos \left(2 \varphi_{2}\right)+\cos \left(2 \varphi_{1}\right) \cos \left(\varphi_{2}\right)$ & $-0.0007183(67)$ \\
\hline 11 & $\sin \left(\varphi_{1}\right) \sin \left(2 \varphi_{2}\right)+\sin \left(2 \varphi_{1}\right) \sin \left(\varphi_{2}\right)$ & $0.0005676(71)$ \\
\hline 12 & $\cos \left(2 \varphi_{1}\right) \cos \left(2 \varphi_{2}\right)$ & $0.0005917(95)$ \\
\hline 13 & $\sin \left(2 \varphi_{1}\right) \sin \left(2 \varphi_{2}\right)$ & $-0.0005528(101)$ \\
\hline 14 & $\cos \left(\varphi_{1}\right) \cos \left(3 \varphi_{2}\right)+\cos \left(3 \varphi_{1}\right) \cos \left(\varphi_{2}\right)$ & $0.0000660(67)$ \\
\hline 15 & $\sin \left(\varphi_{1}\right) \sin \left(3 \varphi_{2}\right)+\sin \left(3 \varphi_{1}\right) \sin \left(\varphi_{2}\right)$ & $-0.0001243(71)$ \\
\hline 16 & $\cos \left(2 \varphi_{1}\right) \cos \left(3 \varphi_{2}\right)+\cos \left(3 \varphi_{1}\right) \cos \left(2 \varphi_{2}\right)$ & $-0.0001930(67)$ \\
\hline 17 & $\sin \left(2 \varphi_{1}\right) \sin \left(3 \varphi_{2}\right)+\sin \left(3 \varphi_{1}\right) \sin \left(2 \varphi_{2}\right)$ & $0.0001550(71)$ \\
\hline 18 & $\cos \left(3 \varphi_{1}\right) \cos \left(3 \varphi_{2}\right)$ & $0.0005678(95)$ \\
\hline 19 & $\sin \left(3 \varphi_{1}\right) \sin \left(3 \varphi_{2}\right)$ & $-0.0003813(99)$ \\
\hline 20 & $\cos \left(\varphi_{1}\right) \cos \left(4 \varphi_{2}\right)+\cos \left(4 \varphi_{1}\right) \cos \left(\varphi_{2}\right)$ & $0.0001486(67)$ \\
\hline 21 & $\sin \left(\varphi_{1}\right) \sin \left(4 \varphi_{2}\right)+\sin \left(4 \varphi_{1}\right) \sin \left(\varphi_{2}\right)$ & $-0.0001692(71)$ \\
\hline 22 & $\cos \left(2 \varphi_{1}\right) \cos \left(4 \varphi_{2}\right)+\cos \left(4 \varphi_{1}\right) \cos \left(2 \varphi_{2}\right)$ & $-0.0001806(67)$ \\
\hline 23 & $\sin \left(2 \varphi_{1}\right) \sin \left(4 \varphi_{2}\right)+\sin \left(4 \varphi_{1}\right) \sin \left(2 \varphi_{2}\right)$ & $0.0001792(71)$ \\
\hline 24 & $\cos \left(3 \varphi_{1}\right) \cos \left(4 \varphi_{2}\right)+\cos \left(4 \varphi_{1}\right) \cos \left(3 \varphi_{2}\right)$ & $0.0002397(67)$ \\
\hline 25 & $\sin \left(3 \varphi_{1}\right) \sin \left(4 \varphi_{2}\right)+\sin \left(4 \varphi_{1}\right) \sin \left(3 \varphi_{2}\right)$ & $-0.0002189(70)$ \\
\hline 26 & $\cos \left(4 \varphi_{1}\right) \cos \left(4 \varphi_{2}\right)$ & $0.0001294(95)$ \\
\hline 27 & $\sin \left(4 \varphi_{1}\right) \sin \left(4 \varphi_{2}\right)$ & $-0.0001102(99)$ \\
\hline 28 & $\cos \left(\varphi_{1}\right) \cos \left(5 \varphi_{2}\right)+\cos \left(5 \varphi_{1}\right) \cos \left(\varphi_{2}\right)$ & $-0.0000049(67)$ \\
\hline 29 & $\sin \left(\varphi_{1}\right) \sin \left(5 \varphi_{2}\right)+\sin \left(5 \varphi_{1}\right) \sin \left(\varphi_{2}\right)$ & $0.0000237(70)$ \\
\hline 30 & $\cos \left(2 \varphi_{1}\right) \cos \left(5 \varphi_{2}\right)+\cos \left(5 \varphi_{1}\right) \cos \left(2 \varphi_{2}\right)$ & $0.0000722(67)$ \\
\hline 31 & $\sin \left(2 \varphi_{1}\right) \sin \left(5 \varphi_{2}\right)+\sin \left(5 \varphi_{1}\right) \sin \left(2 \varphi_{2}\right)$ & $-0.0000717(70)$ \\
\hline 32 & $\cos \left(3 \varphi_{1}\right) \cos \left(5 \varphi_{2}\right)+\cos \left(5 \varphi_{1}\right) \cos \left(3 \varphi_{2}\right)$ & $-0.0001440(67)$ \\
\hline 33 & $\sin \left(3 \varphi_{1}\right) \sin \left(5 \varphi_{2}\right)+\sin \left(5 \varphi_{1}\right) \sin \left(3 \varphi_{2}\right)$ & $0.0001380(70)$ \\
\hline 34 & $\cos \left(4 \varphi_{1}\right) \cos \left(5 \varphi_{2}\right)+\cos \left(5 \varphi_{1}\right) \cos \left(4 \varphi_{2}\right)$ & $-0.0001121(68)$ \\
\hline 35 & $\sin \left(4 \varphi_{1}\right) \sin \left(5 \varphi_{2}\right)+\sin \left(5 \varphi_{1}\right) \sin \left(4 \varphi_{2}\right)$ & $0.0001062(70)$ \\
\hline 36 & $\cos \left(5 \varphi_{1}\right) \cos \left(5 \varphi_{2}\right)$ & $0.0001291(96)$ \\
\hline 37 & $\sin \left(5 \varphi_{1}\right) \sin \left(5 \varphi_{2}\right)$ & $-0.0001385(99)$ \\
\hline 38 & $\cos \left(\varphi_{1}\right) \cos \left(6 \varphi_{2}\right)+\cos \left(6 \varphi_{1}\right) \cos \left(\varphi_{2}\right)$ & $-0.0000196(67)$ \\
\hline
\end{tabular}


TABLE S2: continued: Coefficients of the two-dimensional Fourier expansion for the energy potential surface calculated at the MP2/6-311++G(d,p) level of theory (Fig. 3).

\begin{tabular}{llr}
\hline $\mathrm{Nr}$ & Coefficient & \multicolumn{1}{c}{ Value } \\
\hline 39 & $\sin \left(\varphi_{1}\right) \sin \left(6 \varphi_{2}\right)+\sin \left(6 \varphi_{1}\right) \sin \left(\varphi_{2}\right)$ & $0.0000011(70)$ \\
40 & $\cos \left(2 \varphi_{1}\right) \cos \left(6 \varphi_{2}\right)+\cos \left(6 \varphi_{1}\right) \cos \left(2 \varphi_{2}\right)$ & $0.0000058(67)$ \\
41 & $\sin \left(2 \varphi_{1}\right) \sin \left(6 \varphi_{2}\right)+\sin \left(6 \varphi_{1}\right) \sin \left(2 \varphi_{2}\right)$ & $0.0000005(70)$ \\
42 & $\cos \left(3 \varphi_{1}\right) \cos \left(6 \varphi_{2}\right)+\cos \left(6 \varphi_{1}\right) \cos \left(3 \varphi_{2}\right)$ & $0.0000508(68)$ \\
43 & $\sin \left(3 \varphi_{1}\right) \sin \left(6 \varphi_{2}\right)+\sin \left(6 \varphi_{1}\right) \sin \left(3 \varphi_{2}\right)$ & $-0.0000762(70)$ \\
44 & $\cos \left(4 \varphi_{1}\right) \cos \left(6 \varphi_{2}\right)+\cos \left(6 \varphi_{1}\right) \cos \left(4 \varphi_{2}\right)$ & $0.0000854(67)$ \\
45 & $\sin \left(4 \varphi_{1}\right) \sin \left(6 \varphi_{2}\right)+\sin \left(6 \varphi_{1}\right) \sin \left(4 \varphi_{2}\right)$ & $-0.0000778(70)$ \\
46 & $\cos \left(5 \varphi_{1}\right) \cos \left(6 \varphi_{2}\right)+\cos \left(6 \varphi_{1}\right) \cos \left(5 \varphi_{2}\right)$ & $-0.0000879(68)$ \\
47 & $\sin \left(5 \varphi_{1}\right) \sin \left(6 \varphi_{2}\right)+\sin \left(6 \varphi_{1}\right) \sin \left(5 \varphi_{2}\right)$ & $0.0000832(69)$ \\
48 & $\cos \left(6 \varphi_{1}\right) \cos \left(6 \varphi_{2}\right)$ & $0.0000521(96)$ \\
49 & $\sin \left(6 \varphi_{1}\right) \sin \left(6 \varphi_{2}\right)$ & $-0.0000375(98)$ \\
\hline \hline
\end{tabular}


TABLE S3: Coefficients of the two-dimensional Fourier expansion for the energy potential surface calculated at the B3LYP /6-311++G(d,p) level of theory (Fig. 6).

\begin{tabular}{|c|c|c|}
\hline $\mathrm{Nr}$ & Coefficient & Value \\
\hline 1 & 1 & $-271.8628216(13)$ \\
\hline 2 & $\cos \left(\varphi_{1}\right)+\cos \left(\varphi_{2}\right)$ & $-0.0023493(13)$ \\
\hline 3 & $\cos \left(2 \varphi_{1}\right)+\cos \left(2 \varphi_{2}\right)$ & $0.0002507(13)$ \\
\hline 4 & $\cos \left(3 \varphi_{1}\right)+\cos \left(3 \varphi_{2}\right)$ & $-0.0008071(13)$ \\
\hline 5 & $\cos \left(4 \varphi_{1}\right)+\cos \left(4 \varphi_{2}\right)$ & $-0.0001849(13)$ \\
\hline 6 & $\cos \left(5 \varphi_{1}\right)+\cos \left(5 \varphi_{2}\right)$ & $-0.0000245(13)$ \\
\hline 7 & $\cos \left(6 \varphi_{1}\right)+\cos \left(6 \varphi_{2}\right)$ & $0.0000300(13)$ \\
\hline 8 & $\cos \left(\varphi_{1}\right) \cos \left(\varphi_{2}\right)$ & $0.0014733(26)$ \\
\hline 9 & $\sin \left(\varphi_{1}\right) \sin \left(\varphi_{2}\right)$ & $-0.0005921(27)$ \\
\hline 10 & $\cos \left(\varphi_{1}\right) \cos \left(2 \varphi_{2}\right)+\cos \left(2 \varphi_{1}\right) \cos \left(\varphi_{2}\right)$ & $-0.0006350(19)$ \\
\hline 11 & $\sin \left(\varphi_{1}\right) \sin \left(2 \varphi_{2}\right)+\sin \left(2 \varphi_{1}\right) \sin \left(\varphi_{2}\right)$ & $0.0004722(19)$ \\
\hline 12 & $\cos \left(2 \varphi_{1}\right) \cos \left(2 \varphi_{2}\right)$ & $0.0005024(26)$ \\
\hline 13 & $\sin \left(2 \varphi_{1}\right) \sin \left(2 \varphi_{2}\right)$ & $-0.0004539(27)$ \\
\hline 14 & $\cos \left(\varphi_{1}\right) \cos \left(3 \varphi_{2}\right)+\cos \left(3 \varphi_{1}\right) \cos \left(\varphi_{2}\right)$ & $0.0000639(19)$ \\
\hline 15 & $\sin \left(\varphi_{1}\right) \sin \left(3 \varphi_{2}\right)+\sin \left(3 \varphi_{1}\right) \sin \left(\varphi_{2}\right)$ & $-0.0000543(19)$ \\
\hline 16 & $\cos \left(2 \varphi_{1}\right) \cos \left(3 \varphi_{2}\right)+\cos \left(3 \varphi_{1}\right) \cos \left(2 \varphi_{2}\right)$ & $-0.0001415(19)$ \\
\hline 17 & $\sin \left(2 \varphi_{1}\right) \sin \left(3 \varphi_{2}\right)+\sin \left(3 \varphi_{1}\right) \sin \left(2 \varphi_{2}\right)$ & $0.0001191(19)$ \\
\hline 18 & $\cos \left(3 \varphi_{1}\right) \cos \left(3 \varphi_{2}\right)$ & $0.0004753(26)$ \\
\hline 19 & $\sin \left(3 \varphi_{1}\right) \sin \left(3 \varphi_{2}\right)$ & $-0.0003669(27)$ \\
\hline 20 & $\cos \left(\varphi_{1}\right) \cos \left(4 \varphi_{2}\right)+\cos \left(4 \varphi_{1}\right) \cos \left(\varphi_{2}\right)$ & $0.0001153(19)$ \\
\hline 21 & $\sin \left(\varphi_{1}\right) \sin \left(4 \varphi_{2}\right)+\sin \left(4 \varphi_{1}\right) \sin \left(\varphi_{2}\right)$ & $-0.0001096(19)$ \\
\hline 22 & $\cos \left(2 \varphi_{1}\right) \cos \left(4 \varphi_{2}\right)+\cos \left(4 \varphi_{1}\right) \cos \left(2 \varphi_{2}\right)$ & $-0.0001188(18)$ \\
\hline 23 & $\sin \left(2 \varphi_{1}\right) \sin \left(4 \varphi_{2}\right)+\sin \left(4 \varphi_{1}\right) \sin \left(2 \varphi_{2}\right)$ & $0.0001186(19)$ \\
\hline 24 & $\cos \left(3 \varphi_{1}\right) \cos \left(4 \varphi_{2}\right)+\cos \left(4 \varphi_{1}\right) \cos \left(3 \varphi_{2}\right)$ & $0.0001598(18)$ \\
\hline 25 & $\sin \left(3 \varphi_{1}\right) \sin \left(4 \varphi_{2}\right)+\sin \left(4 \varphi_{1}\right) \sin \left(3 \varphi_{2}\right)$ & $-0.0001467(19)$ \\
\hline 26 & $\cos \left(4 \varphi_{1}\right) \cos \left(4 \varphi_{2}\right)$ & $0.0000560(26)$ \\
\hline 27 & $\sin \left(4 \varphi_{1}\right) \sin \left(4 \varphi_{2}\right)$ & $-0.0000555(27)$ \\
\hline 28 & $\cos \left(\varphi_{1}\right) \cos \left(5 \varphi_{2}\right)+\cos \left(5 \varphi_{1}\right) \cos \left(\varphi_{2}\right)$ & $-0.0000148(18)$ \\
\hline 29 & $\sin \left(\varphi_{1}\right) \sin \left(5 \varphi_{2}\right)+\sin \left(5 \varphi_{1}\right) \sin \left(\varphi_{2}\right)$ & $0.0000337(19)$ \\
\hline 30 & $\cos \left(2 \varphi_{1}\right) \cos \left(5 \varphi_{2}\right)+\cos \left(5 \varphi_{1}\right) \cos \left(2 \varphi_{2}\right)$ & $0.0000663(18)$ \\
\hline 31 & $\sin \left(2 \varphi_{1}\right) \sin \left(5 \varphi_{2}\right)+\sin \left(5 \varphi_{1}\right) \sin \left(2 \varphi_{2}\right)$ & $-0.0000665(19)$ \\
\hline 32 & $\cos \left(3 \varphi_{1}\right) \cos \left(5 \varphi_{2}\right)+\cos \left(5 \varphi_{1}\right) \cos \left(3 \varphi_{2}\right)$ & $-0.0000984(18)$ \\
\hline 33 & $\sin \left(3 \varphi_{1}\right) \sin \left(5 \varphi_{2}\right)+\sin \left(5 \varphi_{1}\right) \sin \left(3 \varphi_{2}\right)$ & $0.0000954(19)$ \\
\hline 34 & $\cos \left(4 \varphi_{1}\right) \cos \left(5 \varphi_{2}\right)+\cos \left(5 \varphi_{1}\right) \cos \left(4 \varphi_{2}\right)$ & $-0.0000546(18)$ \\
\hline 35 & $\sin \left(4 \varphi_{1}\right) \sin \left(5 \varphi_{2}\right)+\sin \left(5 \varphi_{1}\right) \sin \left(4 \varphi_{2}\right)$ & $0.0000534(19)$ \\
\hline 36 & $\cos \left(5 \varphi_{1}\right) \cos \left(5 \varphi_{2}\right)$ & $0.0000684(26)$ \\
\hline 37 & $\sin \left(5 \varphi_{1}\right) \sin \left(5 \varphi_{2}\right)$ & $-0.0000666(27)$ \\
\hline 38 & $\cos \left(\varphi_{1}\right) \cos \left(6 \varphi_{2}\right)+\cos \left(6 \varphi_{1}\right) \cos \left(\varphi_{2}\right)$ & $-0.0000072(18)$ \\
\hline
\end{tabular}


TABLE S3: continued: Coefficients of the two-dimensional Fourier expansion for the energy potential surface calculated at the B3LYP /6-311++G(d,p) level of theory (Fig. 6).

\begin{tabular}{llr}
\hline $\mathrm{Nr}$ & Coefficient & \multicolumn{1}{c}{ Value } \\
\hline 39 & $\sin \left(\varphi_{1}\right) \sin \left(6 \varphi_{2}\right)+\sin \left(6 \varphi_{1}\right) \sin \left(\varphi_{2}\right)$ & $0.0000053(19)$ \\
40 & $\cos \left(2 \varphi_{1}\right) \cos \left(6 \varphi_{2}\right)+\cos \left(6 \varphi_{1}\right) \cos \left(2 \varphi_{2}\right)$ & $-0.0000048(18)$ \\
41 & $\sin \left(2 \varphi_{1}\right) \sin \left(6 \varphi_{2}\right)+\sin \left(6 \varphi_{1}\right) \sin \left(2 \varphi_{2}\right)$ & $0.0000040(19)$ \\
42 & $\cos \left(3 \varphi_{1}\right) \cos \left(6 \varphi_{2}\right)+\cos \left(6 \varphi_{1}\right) \cos \left(3 \varphi_{2}\right)$ & $0.0000437(18)$ \\
43 & $\sin \left(3 \varphi_{1}\right) \sin \left(6 \varphi_{2}\right)+\sin \left(6 \varphi_{1}\right) \sin \left(3 \varphi_{2}\right)$ & $-0.0000514(19)$ \\
44 & $\cos \left(4 \varphi_{1}\right) \cos \left(6 \varphi_{2}\right)+\cos \left(6 \varphi_{1}\right) \cos \left(4 \varphi_{2}\right)$ & $0.0000468(19)$ \\
45 & $\sin \left(4 \varphi_{1}\right) \sin \left(6 \varphi_{2}\right)+\sin \left(6 \varphi_{1}\right) \sin \left(4 \varphi_{2}\right)$ & $-0.0000501(19)$ \\
46 & $\cos \left(5 \varphi_{1}\right) \cos \left(6 \varphi_{2}\right)+\cos \left(6 \varphi_{1}\right) \cos \left(5 \varphi_{2}\right)$ & $-0.0000494(19)$ \\
47 & $\sin \left(5 \varphi_{1}\right) \sin \left(6 \varphi_{2}\right)+\sin \left(6 \varphi_{1}\right) \sin \left(5 \varphi_{2}\right)$ & $0.0000495(19)$ \\
48 & $\cos \left(6 \varphi_{1}\right) \cos \left(6 \varphi_{2}\right)$ & $0.0000283(26)$ \\
49 & $\sin \left(6 \varphi_{1}\right) \sin \left(6 \varphi_{2}\right)$ & $-0.0000271(27)$ \\
\hline \hline
\end{tabular}


TABLE S4: Observed frequencies (obs) of diethyl ketone in the frequency range from 31.4 to $36.0 \mathrm{GHz}$ using the scan mode of the spectrometer [12]. Observed - calculated values as obtained after a fit with xiam. The fitted rotational constants are given below the frequencies.

\begin{tabular}{|c|c|c|c|c|c|c|c|}
\hline \multicolumn{3}{|c|}{ upper level } & \multicolumn{3}{|c|}{ lower level } & $\begin{array}{c}\text { obs } \\
\mathrm{GHz}\end{array}$ & $\begin{array}{c}\text { obs-calc } \\
\mathrm{MHz}\end{array}$ \\
\hline 8 & 1 & 8 & 7 & 0 & 7 & 31.62900 & -0.4167 \\
\hline 3 & 2 & 2 & 2 & 1 & 1 & 31.68750 & 0.0817 \\
\hline 12 & 1 & 11 & 11 & 2 & 10 & 31.75963 & -0.0149 \\
\hline 15 & 1 & 14 & 15 & 0 & 15 & 32.02475 & -0.1852 \\
\hline 11 & 3 & 8 & 11 & 2 & 9 & 32.15600 & -0.5596 \\
\hline 10 & 0 & 10 & 9 & 1 & 9 & 32.35700 & 0.0422 \\
\hline 3 & 2 & 1 & 2 & 1 & 2 & 32.58225 & 0.3415 \\
\hline 10 & 3 & 7 & 10 & 2 & 8 & 32.97425 & -0.3261 \\
\hline 9 & 3 & 6 & 9 & 2 & 7 & 33.67625 & -0.0614 \\
\hline 8 & 3 & 5 & 8 & 2 & 6 & 34.24475 & 0.1448 \\
\hline 7 & 3 & 4 & 7 & 2 & 5 & 34.67725 & 0.2270 \\
\hline 4 & 2 & 3 & 3 & 1 & 2 & 34.88500 & 0.4553 \\
\hline 6 & 3 & 3 & 6 & 2 & 4 & 34.98400 & 0.1270 \\
\hline 5 & 3 & 2 & 5 & 2 & 3 & 35.18500 & 0.4845 \\
\hline 4 & 3 & 1 & 4 & 2 & 2 & 35.30300 & 0.0645 \\
\hline 3 & 3 & 0 & 3 & 2 & 1 & 35.36275 & -0.8936 \\
\hline 4 & 3 & 2 & 4 & 2 & 3 & 35.42875 & -0.6203 \\
\hline 4 & 3 & 1 & 4 & 2 & 3 & 35.43150 & 1.0064 \\
\hline 5 & 3 & 3 & 5 & 2 & 4 & 35.47600 & -0.0400 \\
\hline \multirow[t]{4}{*}{8} & 3 & 6 & 8 & 2 & 7 & 35.87175 & 0.0607 \\
\hline & \multicolumn{4}{|c|}{$\mathrm{A} / \mathrm{GHz}$} & & \multicolumn{2}{|c|}{$8.892310(28)$} \\
\hline & \multicolumn{4}{|c|}{$\mathrm{B} / \mathrm{GHz}$} & & \multicolumn{2}{|c|}{$1.954112(13)$} \\
\hline & \multicolumn{4}{|c|}{$\mathrm{C} / \mathrm{GHz}$} & & \multicolumn{2}{|c|}{$1.670162(14)$} \\
\hline
\end{tabular}

